УДК 544.544:543.654

\title{
ЯБЛОКИ С КРАСНОЙ МЯКОТЬЮ КАК ИСТОЧНИК АНТОЦИАНОВ
}

\author{
() В.И. Дейнека ${ }^{*}$, Н.М. Соломатин ${ }^{2}$, Л.А. Дейнека ${ }^{1}$, В.Н. Сорокопудов ${ }^{1}$, С.Л. Макаревич ${ }^{1}$ \\ ${ }^{1}$ Белгородский государственный национальный исследовательский \\ университет, Белгород, ул. Победы, 15, 308015 (Россия), \\ e-mail:deineka@bsu.edu.ru \\ ${ }^{2}$ Мичуринский государственный аграрный университет, Тамбовская \\ область, Мичуринск, ул. Интернациональная, 101, 393760 (Россия) \\ e-mail:nikolavsol@mail.ru
}

В работе исследованы плоды нескольких гибридных яблонь из коллекции Мичуринского ГАУ, генетически связанных с яблоней Недзвецкого (M. niedzwetzkyana). Плоды были отобраны по одному признаку - окрашивание мякоти в характерный для антоцианов красный цвет. При этом наивысший уровень накопления антоцианов 0,070 г на 100 г свежих плодов был найден для плодов яблони сорта «Гранатное». Основным компонентом комплекса является цианидин-3-галактозид (его доля превышает 84\%); концентрация остальных антоцианов - также производных цианидина (включая полимерную форму) существенно ниже. Антоциановый состав кожуры обычных сортов красных яблок оказался тем же по качественному составу и по соотношению между индивидуальными компонентами. По кислотности и по антиоксидантной активности сок яблони сорта «Гранатное» значительно превосходит соки обычных яблок с красной кожурой, поэтому яблони этого сорта представляют большой интерес для пищевой промышленности.

Ключевые слова: яблоки, антоцианы, красномякотные сорта, антиоксидантная активность, кислотность.

\section{Введение}

Антоцианы в настоящее время привлекают особое внимание как природные колоранты, обладающие мощным антиоксидантным действием [1,2]. По этой причине плоды новых сортов фруктовых растений, обогащенные антоцианами, рассматривают в качестве функциональных продуктов питания [2]. Среди яблок - одних из наиболее популярных в России плодов - хорошо известны сорта с интенсивно красно окрашенной кожурой: «Джонатан», «Макинтош» и др. Но в иностранной литературе имеются сведения о существовании сортов яблок, в которых биосинтез антоцианов эффективно происходит и в мякоти [3]. Генетический анализ показал, что все такие сорта восходят к яблоне Недзвецкого (M. niedzwetzkyana Dieck.) природной форме M. sieversii (Ledeb.) M. Roem., родиной которой считается Центральная Азия [4]. Поскольку антиоксидантная активность антоцианов зависит от их строения, видовой состав антоцианов растительных источников имеет большое значение.

Дейнека Виктор Иванович - доктор химических наук, профессор, e-mail: deineka@bsu.edu.ru

Соломатин Николай Михайлович - кандидат сельскохозяйственных наук, доцент кафедры технологии хранения и переработки продукции растениеводства, e-mail: nikolavsol@mail.ru

Дейнека Людмила Александровна - кандидат химических наук, доцент

Сорокопудов Владимир Николаевич - доктор сельскохозяйственных наук, профессор, зам. директора ботанического сада

Макаревич Сергей Леонидович - аспирант
Анализ литературных данных и наши многолетние исследования [5] свидетельствуют о том, что внутри данного рода растений вариации в видовом составе антоцианов в принципе возможны, но они строго ограничены выбором ферментов из определенного полного базиса, биосинтез которых может с различной эффективностью наследоваться внутри вида. В этом отношении отметим, что по большей части литературных данных все растения трибы яблоневые вне зависимости от уровня накопления антоцианов [5] ведут биосинтез главного компонен-

\footnotetext{
* Автор, с которым следует вести переписку.
} 
та - цианидин-3-галактозида, в меньших количествах синтезируется цианидин-3-арабинозид, цианидин-3глюкозид и цианидин-3-ксилозид.

На кафедре плодоводства Мичуринского государственного аграрного университета в результате многолетней селекционной работы профессором В.И. Будаговским и его последователями были получены несколько сортов зимостойких яблонь, предназначенных для использования в качестве слаборослых клоновых подвоев. Большинство из них характеризуются типичной антоциановой окраской вегетативных и генеративных органов, так как в качестве одной из родительских форм при их селекции использовался полученный еще И.В. Мичуриным (с использованием M. niedzwetzkyana) сорт «Красный штандарт». Целенаправленный отбор гибридов на качественные признаки плодов при этом не проводился, но в последнее время стало очевидным, что полученные «красномясые» гибриды с высоким содержанием антоцианов и других антиоксидантов в плодах могут быть перспективными для закладки садов сырьевого назначения [6].

Цель настоящей работы - определение видового состава и уровня накопления антоцианов в плодах перспективных красномясых гибридов яблони и оценка их антиоксидантной активности.

\section{Экспериментальная часть}

Плоды, использованные в данной работе, были собраны в 2012 г. на опытном участке Мичуринского ГАУ в учхозе «Комсомолец» Мичуринского района Тамбовской области. При этом отбирали стандартные, типичные для каждой формы, не поврежденные болезнями и вредителями плоды в состоянии технической зрелости, в третьей декаде августа. Все изучаемые гибридные формы по срокам созревания относятся к позднелетним.

Сок из яблок выделяли при помощи бытовой соковыжималки. Экстракты антоцианов готовили настаиванием образцов в 0,1 M водном растворе $\mathrm{HCl}$. Сумму антоцианов определяли спектрофотометрическим методом по оптической плотности в максимуме абсорбции и пересчитывали на цианидин-3глюкозид, используя литературное значение коэффициента молярного погашения, $\varepsilon=26900 \mathrm{л}^{\cdot} \mathrm{моль}^{-1} \cdot \mathrm{cm}^{-1}$ [7]. Электронные спектры экстрактов записывали на спектрофотометре СФ-56 в кварцевых кюветах.

Для ВЭЖХ определения антоцианы отделяли от сопутствующих экстрактивных веществ методом твердофазной экстракции на патронах ДИАПАК С18 (БиоХимМак СТ, Москва): патрон активировали, пропуская 5 мл ацетона, кондиционировали 10 мл 0,1 М водного раствора $\mathrm{HCl}$, сорбировали антоцианы из экстракта, промывали 3 мл 0,1 М водного раствора $\mathrm{HCl}$ и десорбировали смесью $20 \%$ ацетонитрила, $20 \%$ муравьиной кислоты в воде (по объему). Полученный экстракт разбавляли 1:1 дистиллированной водой и хранили в бытовом холодильнике.

Определение качественного состава антоцианов яблок проводили с использованием метода обращенно-фазовой ВЭЖХ: хроматограф Agilent 1260 с двумя детекторами - диодно-матричным и массспектрометрическим. Антоцианы разделяли на колонке $250 \times 4,6$ мм Reprosil-Pur C18-AQ, 5 мкм в элюенте 10 об.\% ацетонитлила и 10 об.\% муравьиной кислоты в воде при скорости подачи 1 мл/мин при использовании диодно-матричного детектора. Для записи масс-спектров разделение антоцианов проводили на микроколонке: $150 \times 2,1$ мм SB-18 в том же элюенте при скорости подачи 150 мкл/мин. Масс-спектры записывали в режиме электрораспылительной ионизации и при напряжении на фрагменторе 100 В в режиме сканирования положительных ионов. Параметры газа-осушителя: расход 10 л/мин, температура $350{ }^{\circ} \mathrm{C}$, температура квадруполя $100^{\circ} \mathrm{C}$.

Кислотность яблок определяли кислотно-основным титрованием измельченных блендером яблок в водном растворе раствором щелочи $(\mathrm{NaOH})$ с потенциометрическим контролем точки эквивалентности. Антиоксидантную активность экстрактов определяли амперометрическим методом на приборе «ЦветЯуза-01-АА».

Все численные данные, приведенные в работе, являются средним арифметическим 2-3 параллельных определений.

\section{Обсуждение результатов}

Из исследованных в работе образцов яблок с окрашенной мякотью были приготовлены соки, спектры некоторых из них после разбавления в водном растворе $\mathrm{HCl}(\mathrm{pH}=1)$, представлены на рисунке 1 ; они оказались довольно близкими (с максимумом абсорбции $514 \pm 3$ нм), но не эквивалентными. В общем случае различие в спектрах антоциановых комплексов может быть связано:

во-первых, с присутствием в смеси гликозидов различных алгиконов из трех рядов - пеларгонидинового, цианидинового или дельфинидинового [8]; 
во-вторых, с различным характером гликозилирования (по составу гликозидных радикалов и месту их присоединения к антоцианидину);

в-третьих, с различными вторичными превращениями антоцианов, включая образование пироантоцианов или полимерных антоцианов [9].

Гибриды яблони: 1 - «Гранатное»; 2 - 69-4-450; 3 - Royalty; 4 - спектр слабо сорбируемой части экстракта сорта Royalty; экстракты получены в водном растворе $\mathrm{HCl}(\mathrm{pH}=1)$.

Оценка содержания антоцианов с использованием спектрофотомерии в мировой практике производится по двум подходам [7], в которых разделяют вклад в суммарную абсорбцию мономерных и так называемых «полимерных» антоцианов. По методу дифференциальной спектрофотомерии электронные спектры записывают при двух различных рН (1 и 4,5) в буферных растворах: в первом случае интенсивность абсорбции определяется суммарной концентрацией «мономерных» и «полимерных» форм, а во втором случае предполагается, что абсорбция определяется только полимерной формой. По второму методу интенсивность окраски, связанную с полимерной формой, определяют после обесцвечивания мономерных антоцианов за счет присоединения к ним оксида серы (IV). Все эти методы не лишены недостатков, поскольку спектральные характеристики возможных немономерных компонентов при различных рН заранее не известны. При существовании довольно большого числа публикаций по определению немономерных форм антоцианов найти работы, обобщающие опубликованные данные по электронным спектрам, нам не удалось. В целом при образовании пироантоцианов максимумы абсорбции смещаются гипсохромно, тогда как для продуктов конденсации антоцианов по другим направлениям возможны различные варианты изменения окраски, вплоть до образования синих портисинов (portisin) [9, 10]. Отметим также, что принятый в мировой практике [7] способ выражения концентрации антоцианов в пересчете на один из них (чаще всего - цианидин-3-глюкозид, даже если его нет среди компонентов исследуемой смеси) вообще является условностью, так как коэффициенты молярного погашения большей части антоцианов неизвестны. При этом для прикладных аспектов нет необходимости разделять мономерные и полимерные антоцианы, так как оба типа соединений обладают окраской и наверняка являются антиоксидантами. Но тогда нет оснований для отказа и от оценки концентрации антоцианов по упрощенной схеме - без вычитания абсорбции полимерными формами в пересчете на цианидин-3-глюкозида хлорид (табл. 1).

Отметим, что при высокой степени полимеризации при хроматографировании олигомерных антоцианов возможны эксклюзионные эффекты, благодаря чему такие вещества могут быть отделены от мономерных антоцианов при твердофазной сорбции. И действительно, при сорбции антоцианов подкисленного сока яблок сорта Royalty (гибрид между яблонями Недзвецкого и кроваво-красной - M. niedzwetskyana х M. atrosanguinea) на патронах ДИАПАК С18 (БиоХимМак СТ, Москва) удалось выделить слабо удерживающуюся фракцию, электронный спектр которой батохромно (на 8 нм) смещен относительно исходной суммы антоцианов (рис. 1). Эту фракцию можно принять за полимерную, что подтверждается результатами масс-спектрометрического детектирования: два основных компонента этой фракции имели сигналы c m/z, равные 737,1 и 707,1 (это соответствует димеризации соответственно 3-гексозида и 3-пентозида цианидина с катехином). Тогда различия в спектрах подкисленных соков яблок на рисунке 1 могут быть связаны с различной долей колорантов, приходящейся на полимерные антоцианы.

Рис. 1. Электронные спектры соков из плодов гибридов яблони с окрашенной мякотью

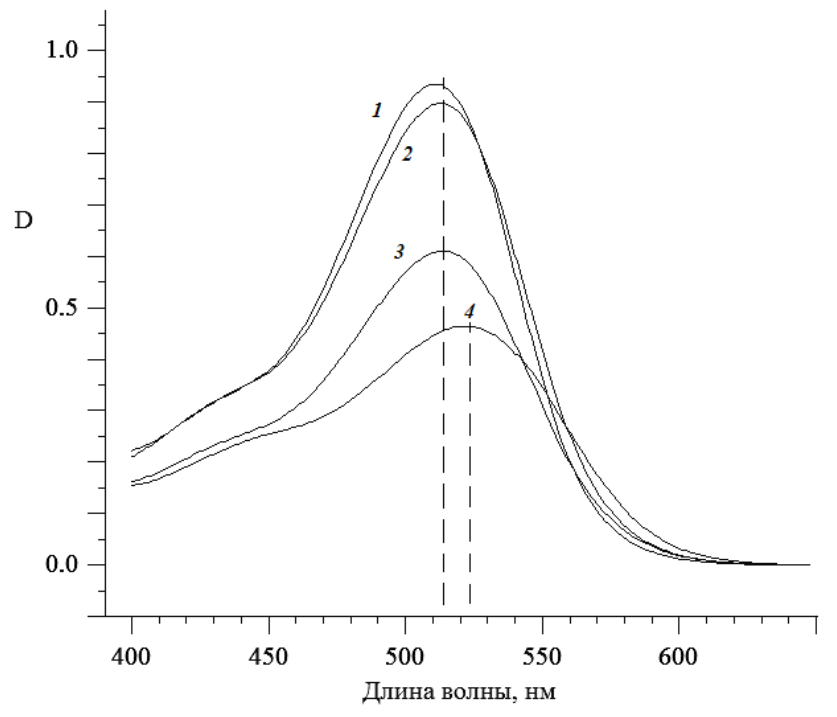


Таблица 1. Антоциановый состав плодов гибридных сортов яблонь

\begin{tabular}{|c|c|c|c|c|c|c|}
\hline Антоцианы & Полим. & Cy3Gal & Cy3Glu & Cy3Ara & Cy3Xyl & \multirow{5}{*}{ Ост. } \\
\hline $\mathrm{t}_{\mathrm{R}}{ }^{*}, \mathrm{мин}$ & $3,0-3,5$ & $5,73 \pm 0,02$ & $6,86 \pm 0,02$ & $8,52 \pm 0,02$ & $15,27 \pm 0,02$ & \\
\hline$\lambda_{\max }{ }^{* *}, \mathrm{HM}$ & 527 & 517 & 517 & 517 & 517 & \\
\hline $\mathrm{m} / \mathrm{z}^{* * *}$ & 707,1 и 737,1 & 449,1 ; & 449, 1 ; & 419,1; & 419,1; & \\
\hline & & 287,0 & 287,0 & 287,0 & 287,0 & \\
\hline \multicolumn{7}{|c|}{ Мольная доля (по площадям пиков на хроматограмме), \%, в некоторых сортах яблок } \\
\hline Royalty & $6,4 \pm 0,4$ & $84,2 \pm 0,4$ & $0,2 \pm 0,1$ & $1,7 \pm 0,2$ & $2,5 \pm 0,2$ & $4,9 \pm 0,2$ \\
\hline Гранатное & $2,8 \pm 0,2$ & $85,6 \pm 0,4$ & $0,2 \pm 0,1$ & $2,8 \pm 0,2$ & $4,4 \pm 0,2$ & $4,2 \pm 0,2$ \\
\hline $87-3-2$ & $6,8 \pm 0,4$ & $74,1 \pm 0,4$ & $0,2 \pm 0,1$ & $3,6 \pm 0,2$ & $8,3 \pm 0,3$ & $7,0 \pm 0,2$ \\
\hline $69-4-450$ & $4,1 \pm 0,2$ & $85,7 \pm 0,5$ & $0,2 \pm 0,1$ & $2,8 \pm 0,2$ & $3,8 \pm 0,2$ & $3,4 \pm 0,2$ \\
\hline $75-1-65$ & $5,4 \pm 0,3$ & $82,2 \pm 0,2$ & $0,1 \pm 0,1$ & $2,4 \pm 0,2$ & $6,7 \pm 0,2$ & $3,2 \pm 0,2$ \\
\hline
\end{tabular}

- время удерживания в условиях на рис.1; ${ }^{* *}$ - длина волны максимума абсорбции для спектра, записанного в ячейке диодно-матричного детектора; ${ }^{* * *}$ - координаты сигналов в масс-спектре пиков. Полим. - сумма полимерных антоцианов, Cy3Gal - цианидин-3-галактозид, Cy3Glu - цианидин-3-глюкозид, Су3 Ara - цианидин-3-арабинозид, Су3Ху1 цианидин-3-ксилозид.

Анализ хроматографического профиля экстрактов плодов различных сортов яблок с окрашенной мякотью (рис. 3) показал, что все они имеют один и тот же основной антоциан (табл. 1) с характерным для 3-моногликозидов цианидина максимумом абсорбции (517,5 нм, в растворе 10 об.\% НСООН и 10 об.\% $\mathrm{CH}_{3} \mathrm{CN}$ в воде, рис. 2). Принадлежность этого вещества к производным цианидина подтверждается присутствием в масс-спектре сигнала $\mathrm{c} \mathrm{m} / \mathrm{z}=287$ (табл. 2). По масс-спектрометрическим данным это соединение является гексозидом цианидина $(\mathrm{m} / \mathrm{z}=449)$. Его время удерживания совпадает со временем удерживания основного антоциана экстрактов плодов аронии Мичурина (Aronia mitchurinii A. Skvorts. et Maitulina) и плодов ирги обыкновенной (Amelanchier ovalis Medik.), рис. 3, поэтому это вещество можно определить как цианидин-3-галактозид, Cy-3-Gala [5]. Аналогично можно выполнить отнесение некоторых других минорных пиков на хроматограмме экстракта яблок: это содержащийся лишь в относительно небольших количествах цианидин-3-глюкозид, Cy-3-Glu, цианидин-3-арабинозид, Сy-3-Ara, и цианидин-3-ксилозид, Cy-3-Xyl, - т.е. типичные для трибы яблоневые компоненты (рис. 3 и табл. 1).

Антоцианы кожуры трех обычных (с неокрашенной мякотью) популярных сортов яблонь (табл. 2) не только по видовому составу, но и по их соотношениям в сумме колорантов не отличались от рассмотренных выше.

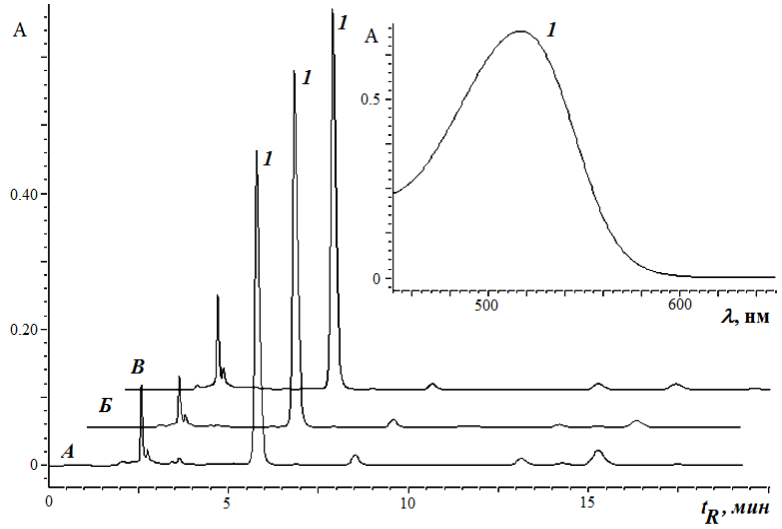

Рис. 2. Разделение компонентов антоциановых комплексов трех сортов яблок. Сорта: $\boldsymbol{A}-87-3-2$; $\boldsymbol{B}$ - 69-4-450; $\boldsymbol{B}$ - Royalty; 1 - цианидин-3галактозид. Колонка $250 \times 4$ мм Reprosil-Pur C18-AQ, 5 мкм. Подвижная фаза: 10 об.\% $\mathrm{CH}_{3} \mathrm{CN}$, 10 об.\% НСООН в воде; 1 мл/мин. Детектор: 515 нм. В правом верхнем углу - электронный спектр, записанный в ячейке диодно-матричного детектора

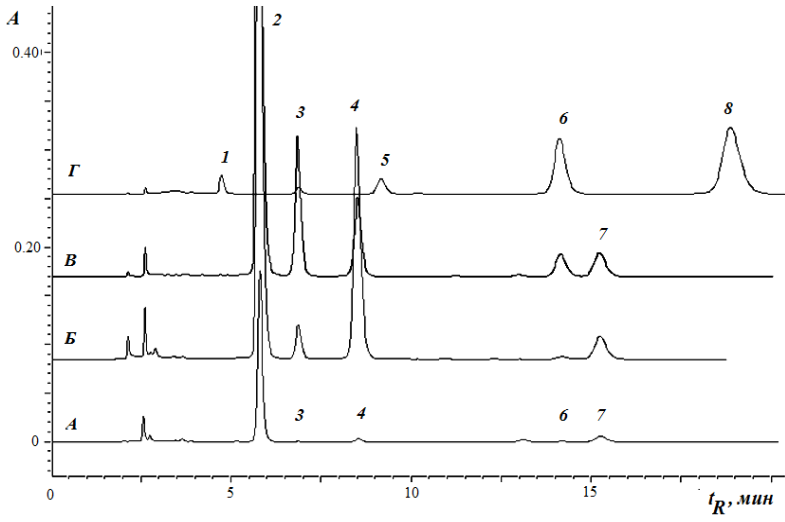

Рис. 3. Разделение антоцианов комплексов плодов четырех растений: $\boldsymbol{A}$ - плоды яблони формы 75-165; $\boldsymbol{Б}$ - плоды аронии Мичурина (Aronia mitchurinii A. Skvorts. et Maitulina); В - плоды ирги обыкновенной (Amelanchier ovalis Medik.), $\boldsymbol{\Gamma}$ - плоды винограда неизвестного сорта. 1 - дельфиниидн-3-глюкозид; 2 - цианидин-3галактозид; 3 - цианидин-3-глюкозид; 4 - цианидин-3-арабинозид; 5 - петунидин-3глюкозид; 6 - пеонидин-3-глюкозид; 7 - цианидин-3-ксилозид; 8 - мальвидин-3глюкозид 
Таблица 2. Сопоставление свойств обычных и красномясых сортов яблок

\begin{tabular}{c|l|c|c|c}
\hline \multirow{2}{*}{$№$} & \multicolumn{1}{|c|}{ Сорт } & Содержание антоцианов, г на 100 г & \multirow{2}{*}{ Кислотность*, масс. \% } \\
\cline { 3 - 4 } & & в кожуре & в плоде & $0,36 \pm 0,03$ \\
2 & «Память Мичурина» & $0,36 \pm 0,01$ & $0,041 \pm 0,003$ & $0,45 \pm 0,01$ \\
3 & «Макинтош» & $0,56 \pm 0,02$ & $0,052 \pm 0,003$ & $0,52 \pm 0,01$ \\
4 & «обо» & $0,36 \pm 0,01$ & $0,037 \pm 0,002$ & $1,66 \pm 0,03$ \\
5 & «ранатное» & - & $0,070 \pm 0,003$ & $1,83 \pm 0,02$ \\
\hline
\end{tabular}

* - в пересчете на яблочную кислоту

Концентрация антоцианов в кожуре была довольно высокой, так что в целом уровень их накопления на массу яблока оказался лишь в 1,5-2 раза меньше, чем в лучшем из сортов «красномясых» яблок. В полном соответствии с уровнем накопления антоцианов антиоксидантная активность сока яблок сорта «Гранатное» оказалась примерно в два раза выше, чем сока яблок сорта Память Мичурина - 34,6 и 18,0 мг в пересчете на аскорбиновую кислоту на 1 г плода, соответственно.

Еще одна отличительная черта плодов яблок сорта «Гранатное» (как и Royalty) - существенно более высокая кислотность (табл. 2), что не удивительно, поскольку именно кислая среда способствует сохранности антоцианов.

\section{Выводы}

Таким образом, плоды яблони сорта «Гранатное», собранные в 2012 г. на опытном участке Мичуринского ГАУ в учхозе «Комсомолец» Мичуринского района Тамбовской области, накапливают до 0,07 г на 100 г антоцианов в мякоти. Основной антоциан комплекса - цианидин-3-галактозид (его доля превышает 84\%); концентрация остальных антоцианов - также производных цианидина (включая полимерную форму) существенно ниже. По кислотности и по антиоксидантной активности сок яблони сорта «Гранатное» значительно превосходит соки обычных яблок с красной кожурой, поэтому яблони этого сорта представляют большой интерес для пищевой промышленности.

\section{Список литературы}

1. Stintzing F.C., Stintzing A.S., Carle R., Frei B., Wrolstad R.E. Color and antioxidant properties of cyanidin-based anthocyanin pigments // J. Agric. Food Chem. 2002. Vol. 50. Pp. 6172-6181.

2. Rodriguez E.B., Flavier M.E., Rodriguez-Amaya D.B., Amaya-Farfán J. Phytochemicals and functional foods. Current situation and prospect for developing countries // Segurança Aliment. Nutric. Camp. 2006. Vol. 13. Pp. 1-22.

3. Mulabagal V., Van Nocker S., Dewitt D. L., Nair M.G. Cultivars of apple fruits that are not marketed with potential for anthocyanin production // J. Agric. Food Chem. 2007. Vol. 55. Pp. 8165-8169.

4. van Nocker S., Berry G., Najdowski J., Michelutti R., Luffman M., Forsline P., Alsmairat N., Beaudry R., Nair M.G., Ordidge M. Genetic diversity of red-fleshed apples (Malus) // Euphytica. 2012. Vol. 185. Pp. 281-293.

5. Дейнека В.И., Григорьев А.М., Дейнека Л.А., Ермаков А.М., Сиротин А.А., Староверов В.М. Анализ компонентного состава антоцианов плодов и жирных кислот масел семян некоторых видов семейства Rosaceae методом высокоэффективной жидкостной хроматографии // Растительные ресурсы. 2005. Вып. 1. С. 91-98.

6. Иванов А.А., Верзилин А.В. Содержание биологически активных веществ в плодах у форм яблони, перспективных для создания сырьевых садов // Слаборослое садоводство. Материалы международной научнопрактической конференции 23-24 июня 1999 г. Мичуринск, 1999. ч. 2. С. 82-84.

7. Giusti M.M., Wrolstad R.E. Characterization and Measurement of Anthocyanins by UV-Visible Spectroscopy // Current Protocols in Food Analytical Chemistry, R. E. Wrolstad (Ed.), John Wiley \& Sons, NY, 2001. F1.2.1-F1.2.13.

8. Дейнека Л.А., Литвин Ю.Ю., Дейнека В.И. Критерии для классификации винограда по антоциановому комплексу плодов // Научные ведомости БелГУ. Серия: Естественные науки. 2008. №7(47). Вып. 7. С. 71-78.

9. He F., Pan Q.-H., Shi Y., Duan C.-Q. Chemical Synthesis of Proanthocyanidins in Vitro and Their Reactions in Aging Wines // Molecules. 2008. Vol. 13. Pp. 3007-3032.

10. He F., Liang N.-N., Mu L., Pan Q.-H., Wang J., Reeves M.J., Duan C.-Q. Anthocyanins and Their Variation in Red Wines II. Anthocyanin Derived Pigments and Their Color Evolution // Molecules. 2012. Vol. 17. Pp. 1483-1519. 
Dejneka V.I. ${ }^{\text {I* }}$, Solomatin N.M. ${ }^{2}$, Dejneka L.A. ${ }^{l}$, Sorokopudov V.N. ${ }^{l}$, Makarevich S.L. ${ }^{l}$ RED-FLESH APPLES AS A SOURCE OF ANTHOCYANINS

${ }^{I}$ Belgorod State University, Belgorod, Victory, 15, 308015 (Russia) e-mail: deineka@bsu.edu.ru

${ }^{2}$ Michurinsky State Agrarian University, Tambov region, Michurinsk, Internatsionalnaya, 101, 393760 (Russia) e-mail: nikolavsol@mail.ru

Fruits of some cultivars of red-flesh apples derived from Malus niedzwetzkyana were found to accumulate up to $0,070 \mathrm{~g}$ per $100 \mathrm{~g}$ (for that of «Granatnoye» variety). The main component of all samples under investigation was found to be cyanindin-3-galactoside (more than $84 \%$ of anthocyanins sum) among some others cyanidin derivatives. The titrable acidity as well as antioxidant activity of «Granatnoye» fruits juice exceeded that for ordinary varieties (including red-skin ones); thus the former is of great interest for food industry.

Keywords: apples, anthocyanins, red-flashed varieties, antioxidant activity, acidity.

\section{References}

1. $\quad$ Stintzing F.C., Stintzing A.S., Carle R., Frei B., Wrolstad R.E. J. Agric. Food Chem., 2002, vol. 50, pp. 6172-6181.

2. Rodriguez E.B., Flavier M.E., Rodriguez-Amaya D.B., Amaya-Farfán J. Segurança Aliment. Nutric. Camp., 2006, vol. 13, pp. 1-22.

3. Mulabagal V., Van Nocker S., Dewitt D.L., Nair M.G. J. Agric. Food Chem., 2007, vol. 55, pp. 8165-8169.

4. van Nocker S., Berry G., Najdowski J., Michelutti R., Luffman M., Forsline P., Alsmairat N., Beaudry R., Nair M.G., Ordidge M. Euphytica, 2012, vol. 185, pp. 281-293.

5. Dejneka V.I., Grigor'ev A.M., Dejneka L.A., Ermakov A.M., Sirotin A.A., Staroverov V.M. Rastitel'nye resursy, 2005, issue 1, pp. 91-98. (in Russ.)

6. Ivanov A.A., Verzilin A.V. Slaborosloe sadovodstvo. Materialy mezhdunarodnoj nauchno-prakticheskoj konferencii 23 - 24 ijunja 1999. [Grew poorly gardening. Proceedings of the international scientific-practical conference on 23 - 24 June 1999]. Michurinsk, 1999, part 2, pp. 82-84. (in Russ.)

7. Giusti M.M., Wrolstad R.E. Current Protocols in Food Analytical Chemistry, New York, 2001, F1.2.1-F1.2.13.

8. Dejneka L.A., Litvin Ju.Ju., Dejneka V.I. Nauchnye vedomosti BelGU. Serija: Estestvennye nauki, 2008, no. 7(47), issue 7, pp. 71-78. (in Russ.)

9. He F., Pan Q.-H., Shi Y., Duan C.-Q. Molecules, 2008, vol. 13, pp. 3007-3032.

10. He F., Liang N.-N., Mu L., Pan Q.-H., Wang J., Reeves M.J., Duan C.-Q. Molecules, 2012, vol. 17, pp. $1483-1519$. 